American Journal of Economics and Business Administration 3 (2): 420-424, 2011

ISSN 1945-5488

(C) 2011 Science Publications

\title{
Program Evaluation of Health Care Management: Is it adjusted for Students Needs?
}

\author{
${ }^{1}$ Fereshteh Farzianpour, ${ }^{2}$ Hossein Dargahi, ${ }^{2}$ Shadi Hosseini, \\ ${ }^{2}$ Seyead Shahab Hosseini and ${ }^{3}$ Shayan Hosseini \\ ${ }^{1}$ Department of Health Management and Economics, School of Public Health, \\ Tehran University of Medical Sciences, Iran \\ ${ }^{2}$ Department of Health Care Management, \\ Faculty of Allied Medical Sciences, Tehran University of Medical Sciences, Iran \\ ${ }^{3}$ Management of Energy Student, Amirkabir University, Iran
}

\begin{abstract}
Problem statement: Since improving the quality of high education is the final purpose of educational evaluation and an internal evaluation can make it possible to judge the quality of high education and achieve the goal of educational systems, in this study an internal evaluation in health care management department of Allied Medical Sciences Faculty of Tehran University of Medical Sciences, which is responsible for training health care management Students, was conducted. Approach: The study was a descriptive and cross-sectional one which was done in an applied manner in health care management department in 2006. The participants in the study included the manager of the department, the members of evaluation committee ( 3 people), Faculty board members ( 5 people), all the students, graduate students (20 people) and four experts. Nine questions were the tool used in the study. The questions were approved, considering reliability and validity, by means of the internal evaluation software of ministry of health, treatment and medical education. Regarding final approvement, 85percent Cronoch's alpha was obtained. To score the questions in the questionnaire, the researchers used likert choice scale (from completely undesirable to completely desirable). At the end, the data were analyzed using descriptive statistics and SPSS software. Results: Findings indicated that the faculty board members had the highest utility (70\%) and the research factor the lowest $(36.6 \%)$. Conclusion: Considering the factors evaluated, the utility of the department under study was rather high. The SWOT analysis shows that the department can obtain higher scores in later evaluations.
\end{abstract}

Key words: Program evaluation, evaluation committee, SWOT analysis, organizational structure, SPSS software, internal evaluation, learning processes

\section{INTRODUCTION}

One of the most important problems in high educational system is quality. The quality of education is increasingly influenced by factors outside the system (Farzianpour et al., 2011). Although there have been some increases in this area, there is no consensus on the quality management in high educational system (Farzianpour et al., 2010a). In recent years, considering social-economic crises and increase in the number of the students in our country, the importance of the improvement of the high educational system quality has been emphasized more (Farzianpour et al., 2009, Tian et al., 2007; Rittidet, 2011). Since the improvement of the quality causes the organizations, including high education one, to be on competitive edges, many researchers have given their attention to this area (Manjunath et al., 2007; Miller et al., 2009). Considering this fact, conducting an accurate evaluation which can lead to a structural judgment and quality documentation is of special importance (Reeves et al., 2009; Focht and Henderson, 2009).

Beside this fact, changes originating from inside and outside the system have challenged the conventional approaches to management (Sandars et al., 2007; Kazu, 2009). Therefore, an evaluation program involves systematic and complex operations of data gathering, observation, analysis and at the end considering all aspects to be able to judge the quality and to present a solution (Farzianpour et al., 2007; Duangsin et al., 2011) The evaluation framework which has been recommended to make decisions in high education system includes

Corresponding Author: Fereshteh Farzianpour, Department of Health Management and Economics, School of Public Health, Tehran University of Medical Sciences, Iran 
evaluation of the content, evaluation of the data, evaluation of the processes and evaluation of the results (Farzianpour et al., 2004; Nasiri and Deng, 2009).

The usual pattern of evaluation of universities in successful countries including fifteen European countries has the following structure (Farzianpour and Bazargan, 1999; Liaghatdar et al., 2009):

- A national system for coordinating evaluation affairs

- A continuous internal evaluation

- An external evaluation and spread of results

Considering the purpose of internal evaluation, i.e. improvement of quality in all aspects, the researchers decided to conduct an internal evaluation in health care management department in order to improve the quality of education. Of course, some studies have been done by some researchers, including (Abdolvahab et al., 2009; Rabbani et al., 2006; Parsa Yekta et al., 2005; Barazandeh-Tehrani et al., 2006) but none of them has addressed internal evaluation of health care management department of Allied Medical Sciences faculty of Tehran University of Medical Sciences. To do internal evaluation of the department, the researchers used a native pattern based on usual international patterns (Farzianpour and Bazargan, 1999; Leung, 2010).

\section{MATERIALS AND METHODS}

The study was a cross-sectional, descriptive one which was conducted in health care management department in 2006. Questionnaire was the tool used together data. The internal evaluation of the department was done based on nine factors: Mission's statement and goals, management and organizational structure, faculty board members, students, training and learning processes, educational courses and curricula, graduate students, educational and research facilities and equipment and research together with 52 criteria and 131 indicators.

The participants in the study included the manager of the department, the members of evaluation committee ( 3 people), Faculty board members (5 people), all the students, graduate students (20 people) and four experts. The questions included in the questionnaire were developed separately for the following groups: The manager of the department, the members of the evaluation committee, the faculty board members, students, graduate students and experts. The questions were approved, considering reliability and validity, by means of the internal evaluation software of ministry of health, treatment and medical education Regarding final improvement,
$85 \%$ Cronboch's alpha was obtained. To score the questions in the questionnaire, Likert five-choice scale completely undesirable, undesirable, rather desirable, desirable, completely desirable was used. The data were analyzed using descriptive statistics (data description, measuring Percentages and frequencies) and SPSS software.

\section{RESULTS}

Findings of the research concerning the degree of desirability of the nine factors were as follows: Mission's statement and goals (57\%), management and organizational structure $(64.2 \%)$, faculty board members $(70 \%)$, students $(60 \%)$, training and learning processes $(69.5 \%)$, educational courses and curricula $(66.6 \%)$, graduate students $(63.2 \%)$, educational and research facilities and equipment (59/4\%) and research $(36.6 \%)$. The scores are displayed in Table 1 and Fig. 1.

Based on SWOT analysis the results were as follows

\section{Strengths points:}

- Providing and developing strategic planning for the department (2006-2011) and announcing it to the manager of the university

- Presence of faculty board members who are specialist in the field of management and who are experienced due to holding executive positions and so the possibility of transferring their experience to the students through theoretical courses

- Faculty board members' high sensitivity and apprehension concerning planning, organizing, defining and developing organizational goals

- Contribution of all members to performing the activities of the department

- The accessibility of the department manager considering his executive duties and the acting general director of the university as he is one of the instructors in the department, which causes as instructor direct communication with the students, transferring his knowledge and educational and executive experiences to the students as well as informing the students of their rights and duties

- Centralization in using educational equipment and related aids which has produced desirable results

- Existence of a large number of students in the department considering the students who attend in the evening classes

- Existence of particular programs regarding efficient use of the students thesis's 
Table 1: The degree and continuum of desirability of factors which were evaluated in health management and economics department allied medical sciences, Tehran University of Medical Sciences in 2006

\begin{tabular}{lll}
\hline Evaluated Factors & Degree of desirability & Desirability continuum \\
\hline Mission's statement and goals & Rather desirable \\
Management and organizational structure & Rather desirable & Desirable \\
Faculty board members & 3.85 & Rather desirable \\
Students & 3.53 & Desirable \\
Training and learning processes & 3.01 & Rather desirable \\
Educational courses and curricula & 3.46 & Rather desirable \\
Graduate students & 3.33 & 3.16 \\
Educational and research facilities and equipment & 2.97 & Rather desirable \\
Research & 1.83 & Rather desirable \\
\hline
\end{tabular}

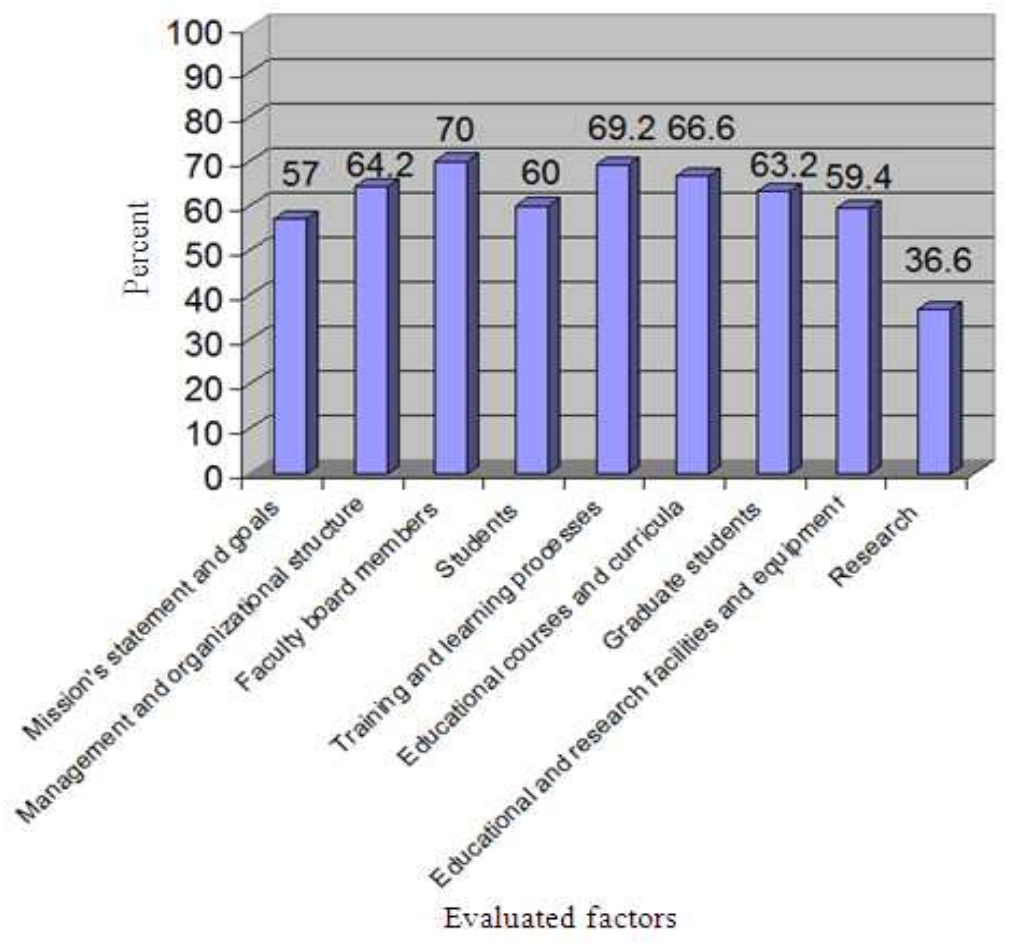

Fig. 1: The percentage of desirability of the evaluated factors in health management and economics department of faculty of allied medical sciences, TUMS in 2006

\section{Weakness points:}

- Of programs of the faculty

- Lack of enough external collaboration including working on educational and research programs common with management and statistics department of health faculty

- Faculty board members involvement in executive positions and so lack of enough opportunity for more interaction with the students

- The students low satisfaction with the faculty board members compared with other criteria

- Lack of access to the feedback of the evaluation results regarding the students, educational progress
- Lack of enough educational and research sources

- Lack of MS and PhD students in the department

- Lack of enough space in the department due to lack of enough educational space in the faculty and university and so the students dissatisfaction

- Lack of enough scientific production in the department

- Lack of connection to the graduate students

\section{Opportunities:}

- The faculty's manager's diligent effort concerning proving educational and research sources and inputs for the department

- Announcing the satisfaction of the organizations with the graduates of this major who work for them 
- The university's management's positive attitude towards the faculty of Allied Medical Sciences

- Executive responsibility of the manger of the department and some of the members concerning providing more sources and possibilities for the department

\section{Threats:}

- Existence of very old faculties which are centers of excellence in our country and which can affect the sources and inputs allocated to faculty of Allied Medical Sciences causes the students to have a negative attitude towards this faculty

- The attitude of some of the board members and authorities of the faculties towards the degree the students should receive (they believe the students should be trained only for M.B. degree)

- Lack of enough exploitation of the physical expansion of Tehran University of Medical Sciences and so lack of enough educational space in health care department

\section{DISCUSSION}

Since through internal evaluation it is possible to remove the problems and establish an efficient educational system (Farzianpour et al., 2004; Rostirolla and Rostirolla, 2011) and also considering the emphasis put on the continuous evaluation of universities and centers of higher education as well as research institutes by Ministry of Health, Treatment and Medical Sciences, internal evaluation of health care management department of Allied Medical Sciences, Tehran University of Medical Sciences was conducted regarding 9 factors, 52 criteria and 131 indicators. The highest degree of desirability was related to the faculty board members $3.53(70 \%)$ ) and the lowest related to research $1.83(36.6 \%)$. The rest factors evaluated were rather desirable.

Tehran University of Medical Sciences enjoys desirability regarding the board of faculty members, but considering the problems with research area, of the research institutes of Iran, this problem is obvious in the department under study.

The results of some researches regarding internal evaluations by Parsa Yekta et al. (2005) (in nursing faculty), Rabbani et al. (2006), (in pediatric department), Farzianpour et al. (2004; 2010b) (in 15 groups of educational public health school) and Barazandeh-Tehrani et al. (2006) (in pharmacy faculty) are completely desirable, desirable, desirable, rather desirable, respectively.

\section{CONCLUSION}

Considering the undeniable role which internal evaluation plays in improving affairs and advancement of educational goals, through revising the indicators with lower scores and also improving the indicators with high scores the quality of education will be improved.

Results: In general, the education department under study is in a rather desirable state but continuing the process of evaluation seems necessary.

Suggestions: The following suggestions can be useful:

- The signing of a contract (agreement) on educational and research collaboration

- Regular timed planning for more contact and interaction of the members of the department with students

- Exploring and offering techniques to increase the students' satisfaction

- Offering regularized designs to use the student's ideas concerning the methodology of the faculty board members in the department

- Increasing the physical space of the department

- More effort on the part of the manager of the Allied Medical Sciences to absorb more sources and possibilities

\section{REFERENCES}

Abdolvahab, M., M. Jalili, L. Dehghan, P. Raji and F. Farzianpour, 2009. Internal evaluation in the department of occupational therapy faculty of rehabilitation Tehran University of medical sciences. J. Modern Rehabilit., 2: 34-39. http://journals.tums.ac.ir/upload_files/pdf/14970.pd $\mathrm{f}$

Barazandeh-Tehrani, M., E. Souri, F. Farzianpour, A. Shafiei and S. Shamsa et al., 2006. Internal evaluation in the department of education, faculty of chemical medicine, Tehran University of medical sciences. J. Res. Educ. Syst., 1: 57-68. http://www.magiran.com

Duangsin, T., S. Chantachon and K. Paengsoi, 2011. Buddhist philosophy: A study of buddha images for perpetuating buddhism in Isan society. J. Soc. Sci., 7: 149-151. DOI: 10.3844/jssp.2011.149.151

Farzianpour, F. and A. Bazargan, 1999. Evaluation of clinical education departments of Tehran hospitals. J. Faculty Med., 57: 72-78. http://journals.tums.ac.ir 
Farzianpour, F., A.A. Zienaloo and M.A. Gilani, 2004. "Evaluation of educational quality of the faculty of medicine of Tehran of Medical Sciences and Health Services based on Polling of graduates of the year 2000". AMEE 2004 Conference: pp: 4152.www.amee.org

Farzianpour, F., A.H. Emami and M.R. Eshraghian, 2009. The satisfaction of medical practitioners from continuing medical education program of tehran university of medical sciences. IRCMJ., 11: 1-6. www.irmj.ir

Farzianpour, F., A.H. Emami and M.R. Eshraghian,, 2007. An of basic and clinical sciences development project at TUMS. J. Res. Educ. Syst., 1: 47-56.www.edc.tums.ac.ir

Farzianpour, F., A.H. Emami, F. Davari-Tanha, S. Hosseini and A.R. Farzanehnejad, 2010a. Educational programs' quality assessment based on graduates' comments. IRCMJ, 12: 302-307. www.irmj.ir

Farzianpour, F., H. Dargahi, N. Eynolahi and S. Aghababa, 2010b. Evaluation in department of health care management in faculty of allied medical sciences Tehran university of medical sciences. J. HIM, 7: 353-360. www.jhim.ir

Farzianpour, F., S. Aghababa, B. Delgoshaei and M. Haghgoo, 2011. Performance evaluation a teaching hospital affiliated to Tehran university of medical sciences based on baldrige excellence model. Am. J. Econ. Bus. Admin., 3: 272-276. DOI: 10.3844/ajebasp.2011. 272-276

Focht, W. and T. Henderson, 2009. Evolution of a graduate environmental science program. Am. J. Environ. Sci., 5: 130-136. DOI: 10.3844/ajessp.2009.130.136

Kazu, I.Y., 2009. The effect of learning styles on education and the teaching process. J. Soc. Sci., 5: 85-94. DOI: 10.3844 jssp.2009.85.94

Leung, C.-H., 2010. Critical factors of implementing knowledge management in school environment: A qualitative study in Hong Kong. Res. J. Inform. Technol., $\quad 2$ : 66-80. http://docsdrive.com/pdfs/academicjournals/rjit/20 10/66-80.pdf

Liaghatdar, M.J., N. Yamani and F. Mohseni, 2009. Cultural foundations of the society and students' ability for establishing EFL teaching in Iranian primary schools. J. Applied Sci., 9: 3385-3390. http://www.doaj.org/doaj?func=abstract\&id=604998

Manjunath, U., B.A. Metri and S. Ramachandran, 2007. Quality management in a healthcare organization: A case of South Indian hospital. TQM Mag., 19: 129-139. DOI: 10.1108/09544780710729971
Miller, W.J., A.T. Sumner and R.H. Deane, 2009. Assessment of quality management practices within the healthcare industry. Am. J. Econ. Bus. Admin., 1: 105-113. DOI: 10.3844/ajebasp.2009.105.113

Nasiri, A. and G. Deng, 2009. Environmental factors influence on mobile learning business. Am. J. Applied Sci., 6: 1225-1234. DOI: 10.3844/ajassp.2009.1225.1234

Olyaei, G.R., M.R. Hadian, F. Farzianpour, S. Jalali and B.V. Gharamaleki et al., 2007. Internal evaluation of the physical therapy department, rehabilitation faculty, Tehran university of medical sciences. Modern Rehabilit. J., 1: 19-24. http://journals.tums.ac.ir

Parsa Yekta, Z., N.S. Barough, Z. Monjamed, F. Farzianpour and M. Eshraghian, 2005. Internal evaluation in faculty of nursing and midwifery, Tehran medical sciences university. Hayat, 11: 7178. http://nursing.tums.ac.ir

Rabbani, A., F. Farzianpour, G. Zamani, A. Zeinaloo and H. Shajari, 2005. Internal evaluation in department of pediatrics faculty of medicine, Tehran University of medical sciences. Iranian J. Pediatr., 16: 301-7. edc.tums.ac.ir/UserFiles/File/evaluation/Farzianpo ur\%20Abstracts5.doc

Reeves, S., M. Zwarenstein, J. Goldman, H. Barr and D. Freeth et al., 2009. Interprofessional Education: Effects on Professional Practice and Health Care Outcomes. Cochrane Database Syst Rev. 23: CD002213. PMID: 18254002

Rittidet, P., 2011. Local youth historical research for students based learning reform, Northeast Thailand. J. Soc. Sci., 7: 224-227. DOI: 10.3844/jssp.2011.224.227

Rostirolla, M. and P. Rostirolla, 2011. A multivariate and multicriterial approach for the SWOT analysis. J. Applied Sci., 11: 719-724. http://www.doaj.org/doaj?func=abstract\&id=69595 4

Sandars, J., M. Langlois and H. Waterman, 2007. Online collaborative learning for healthcare continuing professional development: A cross-case analysis of three case studies. Med. Teach., 29: 917. DOI: $10.1080 / 01421590601045916$

Tian, J., N.L. Atkinson, B. Portnoy and R.S. Gold, 2007. A systematic review of evaluation in formal continuing medical education. J. Contin. Educ. Health Prof., 27: 16-27. DOI: 10.1002/chp.89 